\title{
The Centre for Multilingualism and Diversities Research at the University of the Western Cape, South Africa
}

\author{
Christopher Stroud \\ University of the Western Cape, South Africa
}

cstroud@uwc.ac.za

$\mathrm{T}$ here is an urgency in theorising how diversity is negotiated, communicated, and disputed as a matter of everyday ordinariness that is compounded by the clear linkages between diversity, transformation, voice, agency, poverty and health. The way in which difference is categorised, semiotised and reconfigured in multiple languages across quotidian encounters and in public and media forums is a central dynamic in how poverty and disadvantage are distributed and reproduced across social and racial categorisations. In the South African context, finding ways of productively harnessing diversity in the building of a better society must be a priority.

The South African context with its history of apartheid and on-going contemporary post-apartheid transformation is a veritable laboratory for the study of forms of conflict and conviviality in diversity. South Africa is a society characterised by historical displacements and contemporary mobilities, both social and demographic, where a large part of people's daily life involves negotiating diversity, dislocation, relocation and anomie, while at the same time attempting to pursue aspirations of mobility in a context of continuing inequity.

South Africa recognises the importance of multilingualism and has introduced a number of strategic initiatives to develop competences in a variety of languages across domains and population groups. However, these initiatives do not necessarily translate into greater voice and agency for the citizenry of South Africa. In many respects, a politics of language based on a politics of affirmation or recognition, as in the case of South Africa, compounds and reproduces the very problems it sets out to resolve (e.g. different values of speakers and languages). Furthermore, the nationstate bias of the languages chosen does not easily accommodate or address the problems of migrant and diasporic populations, nor situations arising from digital and mobile communications (across transnational networks). In other words, it is not issues of transformation through (multilingual) agency and voice that have been the corner stone of South African language policy, but rather concerns with 
affirmation of historically disadvantaged languages.

Part of the reason for this is our broad understanding of language and diversity. Historically, multilingualism as a social and political construct has figured significantly in the emergence of competing discourses of colonial and postcolonial citizenship, engaging with a (re)problematisation of citizen and community. It has been allied with social processes that order and regiment peoples into administrative constituencies, in constructing politico- moral images of speakers and in the semiotic framing of discourses of tradition and modernity, agency and citizenship. In other words, different ideas about languages and their linguistic relationships, both functional and formal, as manifested in contesting notions of multilingualism situate varieties/languages in (competing) hierarchical economies of value, determine what languages should/can be mastered by whom, and for what functions and purposes, and constrain modes of access to, and acquisition of, each variety. The organisation of citizenship in societies has been mediated by a historically variable socio-political and cultural organisation of language practices and beliefs about language and language learning.

Not surprisingly, this means that attending to the role of language in bridging divides, restoring dignities and redistributing power poses a host of challenges for contemporary language policy. The conceptual frameworks through which language policy making and implementation are conventionally understood can only with difficulty translate values such as care, empathy, and respect for diversity into a language policy for democracy. Thus, a central question is how can a rethinking of multilingualism contribute to the reconfiguration of public (and intimate) space, so as to allow for a broader based democratic involvement?

\section{THE CENTRE FOR} MULTILINGUALISM AND DIVERSITIES RESEARCH (CMDR)

$\mathrm{T}$ The Faculty of Arts at the University of the Western Cape recently inaugurated the Centre for Multilingualism and Diversities Research, which is dedicated to cross-faculty research on multilingualism. Its overall objective is the development of a theory of language politics adequate for diverse and transforming societies that builds on a more complex understanding of the dynamics of linguistic diversity in its multiple manifestations, local representations and practices, and that provides new modes of theoretical engagement with how speakers accomplish voice and agency, or what constrains or denies this. Importantly, it recognises that a revitalisation and renewal of public and political spaces requires significant contributions from a broad range of humanities, social science and educational disciplines. Colonial and monoglot understandings of language and linguistic diversity have significantly restricted academic engagements with contemporary and historical voices, and the way these voices have been circulated and interpreted for which publics. A critical analysis of contemporary deliberation on multilingualism across academia and society at large will provide the epistemological and methodological framework for the reconstitution of the areas of language, literature and cultural studies from the vantage point/perspective of the global, postcolonial, South. The aim is to embark on a project of intellectual reorientation that promises not just a significant rethinking of multilingualism, but also a new discourse with which to approach interdisciplinary work in the humanities and the education sciences. 


\section{MODES OF WORK}

Cognizant, then, of the double aim of (i) developing an understanding of the wider political and philosophical significance of multilingualism, and (ii) contributing to a disciplinary rejuvenation across the humanities by rethinking language through interdisciplinary dialogue on multilingualism, the CMDR grounds its activities in (a) research clusters, (b) an interdisciplinary seminar series devoted to discipline specific discourses on multilingualism, (c) a programme of visiting researchers and research fellows, (d) a residential writer, (e) international and regional partnerships and (f) outreach activities with local communities and institutions.

\section{RESEARCH CLUSTERS}

$\mathrm{T}$ he work of the Centre is organised into a number of research clusters. Through these research clusters, a cohort of postgraduate students, postdoctoral fellows, and academics working with the new research centre, are establishing an intellectual space to further critical rethinking on what kinds of questions we should be asking of language. This has strengthened existing interdisciplinary projects or led to new ones, and also enabled disciplines and departments to ask challenging questions of themselves.

All research clusters focus on how systems of representation are reflecting and mediating social change (language, literature, music (hip hop), performance, urban semiotics), and how they are being used to forge new perceptions and practices of humanity; in particular, their role in facilitating voice, agency and participative democracy.

An overarching research cluster is that of Linguistic Citizenship, with the other research clusters both contributing to and feeding from the development of the Linguistic Citizenship framework.

\section{Linguistic Citizenship}

The notion of Linguistic Citizen-ship (LC), developed in the context of southern African multilingual contexts, is framed within a so-called politics of transformation. LC refers to how speakers get things done (reshape) or transform their ordinary everyday through a variety of semiotic (multilingual and multimodal) means and in a variety of sites. The notion seeks to counteract much writing on language, democracy and citizenship built on the assumption that only certain forms of language or linguistic practice are politically legitimate for purposes of rational, deliberative discourses in institutionalised public politics. Thus highly variable ways in which speakers attempt to have a voice are ignored or deemphasised. In fact, agency, voice and participation involve modes of speaking that cannot always be accounted for in terms of conventional and fixed linguistic structures, but in practices that are effervescent, momentary and fleeting. Linguistic Citizenship draws attention to the specific features and practices of language that facilitate speaker agency. The term 'linguistic' thus takes on a wider meaning than that conventionally understood by 'language' or 'linguistic' referring to the alternative rhetorical means through which a group may habitually choose to express its voice is not a priori excluded or constrained. Approaches to meaning through Linguistic Citizenship emphasise tracing the emergence of agency and voice at local points of production in a variety of semiotic forms, and the material affordance for this, as well as the en-textualisation of meaning across chains of artefacts and spaces of circulation and how these are resemiotised, and 
transposed. Its emphasis on features of (multilingual and multisemiotic) language use on the margins allows an approach to everyday politics that is better attuned to the complex semiotic world of styles, stances and identities around which people play out their lives. It thus creates the possibility of understanding the rhetorical foundations of radically different types of speaker agency that go 'against the grain' of a conventional politics of language. This research cluster works on the philosophical and political framing of multilingualism in terms of Linguistic Citizenship drawing on the empirical studies and experiences of the other research clusters.

\section{Linguistic landscaping}

Despite global mobility, flow and flux, place, emplacement and locality remain important in many different ways, not least because local place is that through which, and with which, lives take shape, and where biographies of place and life are intimately interwoven. However, local places are fraught and contested constructions, complex and multi-layered, and any physical space will host many different publics living together. Cosmopolitan elites, itinerant guest workers, more permanent diasporic communities and indigenous dwellers participate in unstable, plural settlements characterised by linguistic superdiversity, where the heterogeneity of the community is constantly re-enacted on the form of mixed linguistic repertoires, genres and languages. Contributing to the linguistic heterogeneity is the way in which local linguistic landscapes are semiotically configured through multiple forms of media and material objects, and by images in the form of branded products, advertising and signage that circulate across communities and mediate consumer cultures for a stratified population.
In this research cluster, the complex dynamics of place-making and the structuration of semiotic landscapes are explored, such as the role of signage and the material semiotic landscape in organising place, and how place in turn determines the reading of signage. Of special interest is the idea that a central aspect of place-making is the way affect and movement through space are organised, narrated and interactively accomplished by means of - direct or indirect - engagement with situated material, multilingual semiotic artefacts. Especially important is the question of how place is semiotically constituted as violent or in terms of comfort and safety; how affect serves as a point of navigation in place and is incorporated into narratives of Self and Other across languages; and how 'space /place' structures forms of, and access to literacy and education resources.

\section{Post-apartheid racialisations}

This research cluster explores some ways in which the malleable, permeable and unstable racialisations of contemporary South(ern) Africa are indexed and performed linguistically - that is, how people through language position themselves and are positioned as racial subjects. Specifically, it asks in what ways forms of racial positioning in everyday interactions reproduce or contest the historical faultlines of hegemonic racial discourses of the apartheid state decades after its demise. Do forms of talk, born out of displacement, anomie and contact in the context of South Africa, allow for the articulation of more entangled lifestyles and aspirations that cut across the old faultlines of historically chauvinist identity politics? What are the linguistic building blocks for the emergence of conviviality, and for a politics of association and transformation? How do displaced 
identities in flux find productive points of contact and exchange? One focus is on a new vocabulary for understanding how desire, hope, empathy, structure, and are given semiotic expression? Another theme is the representation and practice of Otherness, especially involving the circulation of hate speech.

\section{Moving words}

This research cluster works with the intertextualities of the past and of (multilingual) narrative as a construction of the present. One focus is developing sufficient intellectual know-how, and sophistication in our analysis of interdiscursivity and translation so as to be able to feed the ideas of African intellectuals, such as S E K Mqhayi, Nontsizi Mgwetho, A C Jordan, David Yali-Manisi and others into the intellectual and literary debate in this country.

\section{Creativity and aesthetics}

A key dynamics for managing contact, conviviality and contest is popular culture. In the South African context, popular culture has been closely connected to the social and political imagination of the country, as well as to emergent public spaces and citizenship practices in which everyone can participate irrespective of status or office. Popular culture is also a site of everyday language crossing, negotiations of linguistic value and indexicality, and language learning. Popular spaces of hip-hop and rap, and similar ludic contexts, both commercial and informal, mobile and multi-modal, thus provide an excellent lens for capturing how languages in encounters of performance are plied in the pursuit of conviviality.

One focus of this research cluster is to understand and tap into the potential of theatre, music and other indigenous and emerging forms of aesthetic performances (hip hop, rap, spaza) in literacies and varieties of African languages, for social, political and intellectual development. Increasingly, theatre and music comprise important arenas for young (South) Africans to exercise their voice and agency, and to express their personalised histories of change and conflict, and their understanding of a transforming continent. An important question from this perspective is how peoples' mobile lives are semiotically assembled? How are semiotic means (sometimes from one language sometimes from another) brought together and reassembled through timespace, across artefacts and modalities?

An important part of this research cluster is concerned with rethinking languages and literatures in (South) African context of social transformation by extending postcolonial literary studies to oral literature and performance, especially literatures in indigenous languages, as currently, postcolonial literary studies has hardly engaged literature and local knowledges written in, for example, Xhosa, Zulu or Tswana.

\section{Multilingual education}

Most speakers' multilingual portfolios present as complexly piecemeal, semiotic traces of their life-histories of personal, social and geographical movement. In such cases, multilingualism manifests as differentiated repertoires of competences in different 'languages' and as truncated complexes of resources where knowledge of language is also partial, depending on speakers' histories of social and geographical trajectories. This means that notions such as mother tongue, first language, second language, with their assumed differences of access and proficiency, no longer adequately capture the ways new emerging multilingual semiotic 
economies are organised, and that the variability and complexity of emerging forms of translocal multilingualism find little resonance in contemporary language educational provisions. Although there are multiple variations of multilingual teaching programs for minority, migrant and community languages, these options have been presented within the discourse of mother tongue, monolingual, bilingual, and multilingual options for education in hierarchically organised typologies.

This research cluster seeks to explore the complexities of language learning and teaching in diverse, postcolonial societies such as South Africa. In particular, we explore how sites of performance, together with notions such as stylisation, stance, and identification, which all emphasise language display, repetition and practice of linguistic form and the re-entextualisation of a routine from one context to another, may replace identity, allegiance and competence as alternative modes of understanding language learning, with implications for notions of speakership and linguistic ownership.

\section{Thesaurus}

The essential task of this research cluster is to create the space for African language studies to speak back to the ignorance and arrogance of monolingual approaches, which - if they read African language texts in translation - read them off as unproblematically Englishlanguage originals. It seeks to develop more complex readings, understandings and practices of linguistic and cultural translation, specifically with respect to the significant stories that remain to be told about the recent social and political past of the country and region.

Another focus is exploring ways of extending the intellectual reach of languages like Afrikaans in order to recover other voices and histories, especially in the Western Cape, but even as far as northern Botswana and Angola, while critically reworking discourses of 'intellectualisation of language'. This theme also seeks to expand thinking on multilingualism, or multivocality beyond different named languages to what Mbembe refers to as 'other languages of power', including those of religion, spirituality, and environmentalism. It thus opens a space for an engagement, say, with literature and discourses of environmentalism, as much as with African biblical hermeneutics, or the Africanisation of Islam and Koran readings.

\section{Pan African forum}

This theme focuses on developing through dialogue with scholars of languages and literatures across the continent new understandings of multilingualism in society. One important focus of research is to uncover the politics and histories of contemporary artefactual stances on African languages through revisiting specifically African language studies which were intellectually impoverished under colonial and apartheid intellectual regimes.

Further, it explores challenges to structural-functional approaches to language and society, as well as suggesting new approaches to language and identity such as dignity and desire as structuring concepts in sociolinguistic identity; the importance of ludic-ness (play) for evolving genres in new technologies in contexts of late-modernity; notions of repertoire, register, genre rather than language; and transmodality in place of multimodality.

This research cluster engages critically with the roles, functions and agency of linguists and the field of linguistics, over and above examining language 
practices in society. On the African continent, linguists have traditionally observed spoken language features in flux and assumed that the speech communities in question were unaware of or did not have strong attachments to a core corpus. In so doing, Western historical documentation masked a long tradition of literary scholarship dating back two thousand years in Ethiopia and to the period between the seventh to sixteenth centuries in the Islamo-Sudanese centres of West and North West Africa as well as to more recent well-established literatures in Southern and Eastern African languages. The historical-political conditions which arrested literary traditions in Africa have exacerbated power differentials amongst languages, stigmatising the local and privileging the global. There is a need to redress historiography in language (undertaken mainly by centre-based scholars) that has not been adequately sensitive to the everyday strategies of linguistic negotiation of the local people. Such an agenda would facilitate a critical interrogation of how the reproduction of inequity is recycled through intricate mechanisms and professional discourses on language to coerce postcolonial complicity.

\section{SEMINAR SERIES}

CMDR runs a seminar series enti4 tled 'Disciplinary Multilingualisms, Interdisciplinary Dialogues' where notions of multilingualism are critically interrogated by providing careful historiographies of linguistic diversity and critical analyses of contemporary deliberations across academia and society at large. The goal is to offer new modes of theoretical engagement with notions of multilingualism that will further investigation into the multivocalities and semiotic seams of language, literary and cultural studies that monolingual modes of inquiry have repressed or been unable to see. Ultimately, the series seeks to establish an intellectual space that will contribute to interdisciplinary work in the humanities, social and education sciences.

\section{WRITER IN RESIDENCE AND FELLOW}

Che CMDR together with the
Programme for Creative Writing at UWC is proud to host Sindiwe Magona as a Fellow and Writer in Residence. (http:// www.multilingdiversities.com/people_researchers.php)

\section{NON-STIPENDIARY FELLOWSHIP PROGRAMME}

The CMDR invites applications from interested researchers (doctoral, postdoctoral) for non-stipendiary fellowships to visit and contribute to the Centre's activities for any period between one and four months. The successful applicant will be attached to one of the core research clusters, and will be part of a wider academic environment (including researchers from the Universities of Cape Town, Stellenbosch and the Cape Peninsula University of Technology) dealing with multilingualism from a variety of perspectives. The Fellow will be expected to give a paper at the CMDR seminar series and undertake to acknowledge the CMDR in any resulting publications. The CMDR will provide visiting fellows with office space and access to computer and internet facilities.

\section{INTERNATIONAL AND REGIONAL PARTNERSHIPS}

$\mathrm{T}$ The CMDR is engaged in a number of international and regional partnerships at different levels of research 
cooperation. It is a member of the 'International Consortium for Language and Diversities' and a founding member of the 'Southern Multilingualism and Diversities Consortium', a grouping of universities and individuals from the geopolitical North and South who work on or in the South. The CMDR has close and active collaborations with local and regional universities in the form of joint supervisions of doctoral candidates, joint seminars and workshops.

\section{LOGAL AND COMMUNITY OUTREACH}

The CMDR works closely with local community and government organisations and schools on questions of multilingualism. One such initiative is the Heal the Hood Project. In a series of joint workshops between the CMDR and hip hop artists, the children of Cape Flats are given the opportunity to discover opportunities in Higher Education through music, and lyrics in different languages. Researchers at CMDR are also actively involved in assisting the community organisation, 'Proudly Manenberg', document and archive their activities as part of local neighbourhood development.

For more information on the Centre for Multilingualism and Diversities Research (CMDR), please visit: http:// www.multilingdiversities.com/index.php 